\title{
EVALUATION OF SPEED-FLOW CHARACTERISTICS ON TWO-LANE HIGHWAYS WITH MIXED TRAFFIC
}

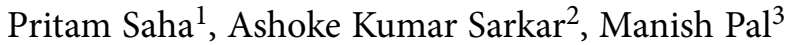 \\ ${ }^{1}$ Dept of Civil Engineering, Indian Institute of Engineering Science and Technology, Shibpur, India \\ ${ }^{2}$ Dept of Civil Engineering, Birla Institute of Technology and Science Pilani, India \\ ${ }^{3}$ Dept of Civil Engineering, National Institute of Technology Agartala, India
}

Submitted 8 July 2013; resubmitted 11 September 2013, 19 January 2014; accepted 28 January 2014; first published online 28 January 2015

\begin{abstract}
The HCM (Highway Capacity Manual 2010) classifies two-lane rural highway that passes through developed areas as 'Class III' and suggests using Percent Free-Flow Speed (PFFS) as performance measure to define Level Of Service (LOS). Apparently, this performance measure addresses the main limitation associated with using Average Travel Speed (ATS) as a measure of performance. However, larger speed differential under heterogeneous traffic causes error in estimating Free-Flow Speed (FFS) and thus affects PFFS. This implication was examined in the present study using field data collected on a national highway approaching a city. Speed-flow equations were developed and intercept values were compared to the FFS obtained according to HCM guidelines. Comparison confirms a very close agreement between average FFS value and those obtained for different types of vehicle separately except for car. This consequently causes an error in estimating PFFS since the traffic composition consists of significant proportion of car. The possible capacity of the highway section was observed to be around $2300 \mathrm{pc} / \mathrm{h}$ for mixed traffic situation.
\end{abstract}

Keywords: two-lane highway; heterogeneous traffic; speed-flow relationship; highway capacity; level of service.

\section{Introduction}

Most of the smaller states in India are capital-centric, even though they are towns or small cities. With the economic growth during the last few years, they are growing quite fast and population from all over the state is settling down for various reasons such as employment, business and education. With the increase in population, the towns/cities are also growing rapidly. Unlike the large cities, usually these towns are having only one highway connectivity (normally two-lane highway) from the other important towns/cities in the state or outside the state and the development takes place along the highway as it provides easy accessibility to the city centre. These areas gradually start to generate considerable amount of traffic as the residents are dependent on the town/city for almost all needs. In the absence of proper planning and lack of sufficient demand to sustain city bus services, the residents usually own bicycles, twowheelers and cars. At the same time, the gap in transport supply is met by para-transit modes such as jeeps, autorickshaws and cycle- rickshaws. Since almost all of them use the highway, the prevailing traffic is mixed in nature and is quite different from other stretches of the same highway or any other in the country as local traffic mixes with traffic passing through the area. In addition, substantial city traffic influence results mobility reduction and subsequent deterioration of quality of service. Thus, the drastic speed reduction on such highways due to the presence of wide range of vehicle category in terms of static and dynamic characteristics in the traffic stream consequences increased risk and higher severity of road accident due to non-adherence to the design speed. The recent edition of HCM (Highway Capacity Manual 2010) classifies this highway section as 'Class III' and provides separate guidelines for performance evaluation.

Traffic operation on two-lane highways is unique as passing manoeuvres are possible only in the face of on-coming traffic in the opposing lane. Thus, two characteristics, passing capacity and passing demand have significant impact on Level Of Service (LOS). The passing demand increases rapidly with the increase in traffic flow as more drivers are caught in platoon. This problem becomes more acute in case of heterogeneous traffic flow when speed differential among different categories of vehicles is quite large. However, as the length of 'Class III' segments is generally limited, passing restrictions are

Corresponding author: Pritam Saha

E-mail: saha.pritam@gmail.com 
not a major concern and also high speeds are not expected. HCM suggests using Percent Free-Flow Speed (PFFS) as performance measure to define LOS on these highways. The logic is if Average Travel Speed (ATS) is close to Free-Flow Speed (FFS), then the interaction among successive vehicles in the traffic stream is small and a high LOS could be expected. By the same token, a lower percentage indicates a higher interaction between vehicles in the traffic stream and therefore a lower LOS. Apparently, this performance measure addresses the main limitation associated with using ATS as a measure of performance. However, larger speed differential under heterogeneous traffic causes error in estimating FFS and thus affects PFFS. Even under similar roadway conditions all vehicles do not have similar FFS due to different characteristics of drivers and vehicles. Clearly, different types of vehicles moving on the same road system enjoy different LOS.

The aim of the current study is, therefore, to develop a better understanding of the FFS of different vehicle category on two-lane highways and their deviation when it is estimated for the heterogeneous traffic stream. Space Mean Speed (SMS) coupled with traffic flow data was extensively collected covering wide range of traffic flow levels and Traditional Model was used to evaluate the speed-flow characteristics on two-lane highways under Indian traffic conditions. At the same time, FFS was also estimated based on the field measurement as HCM recommends. Different category of vehicles was considered separately in order to explore their desired speed under free-flow conditions.

\section{Literature Review}

The relationship between flow rate and speed is fundamental for highway LOS and capacity analysis. After seminal papers on the relationship between three basic variables of traffic flow by Greenshields (1935), many efforts have been made to develop theoretical models during past decades, which include an exponential speed-density model (Greenberg 1959), a transposed exponential model (Underwood 1961), a two-regime model (Edie 1961), and other multi-regime models (e.g., Drake et al. 1967). All these models were developed on the basis of survey data, which indispensably depend on the site characteristics. However, the implications of traffic characteristics had not been sufficiently emphasized. This has significant impact on two-lane highways particularly in developing countries because of heterogeneous traffic mix and behaviour of drivers. A number of studies dealt with these issues in the succeeding decades. Ramanayya (1988) observed that the capacity standards adopted in western countries do not take into account the mixed traffic characteristics prevalent in India. Sarna et al. (1989) emphasized the need of developing highway capacity norms for Indian highways. Kadiyali (1991) observed that vehicle speeds on Indian roads have increased during the past ten years. Speed-flow relationships have also undergone changes. Pursula and Enberg (1991) reported from Finland that the highest flow rate measured on two-lane two-way road was $2500 \mathrm{veh} / \mathrm{h}$ with a directional split of 50/50. Bang et al. (1995) developed speed-flow relationship and simulation model for two-lane road in Indonesia and found that free-flow speed for two-lane roads under ideal conditions is considerably lower in Indonesia than in developed countries. Sahoo et al. (1996) found that increase in traffic volume decreases the speed of vehicles. Parker (1996) observed that knowledge of traffic composition plays an important role in determining capacity. Kumar and Rao (1998a, 1998b) observed that speed density data could be reasonably represented by a linear relationship. Hossain and Iqbal (1999) studied vehicular free speed characteristics on two-lane national highway of Bangladesh. Chandra and Kumar (2003) studied the effect of roadway width on capacity under different volume capacity ratios and varying proportions of vehicles. In a recent study, Velmurugan et al. (2010) developed speedflow equations for different vehicle types on multi-lane highways in India based on traditional and microscopic simulation models.

Furthermore, several studies investigated the freespeed characteristics of vehicles when large speed variation in the traffic stream is observed. Leong (1968) and McLean (1979) found that, for lightly trafficked two-lane roads where most vehicles are travelling freely, coefficient of variation of car speeds ranges from about 0.11 to 0.18. Yagar and Van Aerde (1983) developed equations for the percentile speeds and these were found to be affected by traffic volume, type of vehicles, accessibility, speed limit, existence of an extra lane, and grade. Katti and Raghavachari (1986) observed higher speed dispersion for faster vehicles whereas it was the least for slower vehicles. Similar results are also reported by several other investigators (Pillai, Ramanayya 1977; McLean 1989; Rai Chowdhury 1993). Kumar and Rao (1998a, 1998b) found that the average free speeds of cars, buses, and trucks are approximately 65, 56, and $52 \mathrm{~km} / \mathrm{h}$, respectively. Hossain and Iqbal (1999) conducted a linear regression analysis to explore drivers' free speed relation with the pavement and shoulder widths. It was observed that in case of buses the free speed does not increase with the increase of shoulder width. Based on a study in Taiwan, Tseng et al. (2005) reported that the mean FFS of small vehicles is higher than of larger vehicles. Dey et al. (2006) introduced a parameter 'spread ratio' to predict the bimodality in the speed data in order to have realistic estimate of the vehicular speed under heterogeneous traffic conditions. Madhu et al. (2011) evaluated the changing free-speed characteristics of different vehicles on Indian highways. They developed free-speed equations of different vehicles on different types of multi-lane carriageways.

However, the review of above studies indicates that no studies hitherto considered the combined effect of the heterogeneous traffic, ribbon development and roadside activities while developing speed-flow relationship and subsequent assessment of FFS. Thus, the present study was focused on the speed-flow characteristics of highway portion that passes through developed areas. The free-speed characteristics of different vehicle types were also assessed in the heterogeneous traffic mix. 


\section{Analysis Strategy}

\subsection{FFS Analysis}

At very low flow conditions there is very little interaction among vehicles, and they can travel almost all the time at the speed desired by the drivers. Such traffic conditions can be characterized as free-flow conditions and the speeds are called desired speeds. However, in heterogeneous traffic mix all vehicles are not expected to travel at the same speed even under similar roadway conditions because of different characteristics of drivers and vehicles. As the design speed or posted speed increases, the proportion of slower vehicles is likely to increase. Accordingly, it can be expected that the standard deviation increases as the average FFS increases. A higher standard deviation at higher FFS indicates larger errors in the estimation. Subsequently, considering average FFS while determining PFFS, a performance measure of two-lane highway that passes through developed area, becomes incorrect. Thus, there is a need to resort to FFS value taking different vehicle category into consideration.

HCM presents two methods for the estimation of FFS: field measurements and estimation with guidelines based on the characteristics of the road section. The present study, however, adopts field measurement procedure to estimate FFS. This estimation method assumes that traffic volumes not exceeding $200 \mathrm{pc} / \mathrm{h}$ can be used to approximate free-flow conditions. If the traffic volume exceeds $200 \mathrm{pc} / \mathrm{h}, \mathrm{HCM}$ suggests flow rate correction while estimating the value. FFS was estimated according to HCM (Highway Capacity Manual 2000, 2010) and compared with those obtained from the speed-flow relationship developed for the same highway segment. The percentage error in estimate was thus calculated corresponding to average FFS and the FFS of different vehicle category. As a working hypothesis, the maximum error in the FFS estimate is assumed to be $\pm 10 \%$.

\subsection{Speed-Flow Relationship}

In the present study, the traffic flow data was analysed by typically dividing the traffic volume into two segments

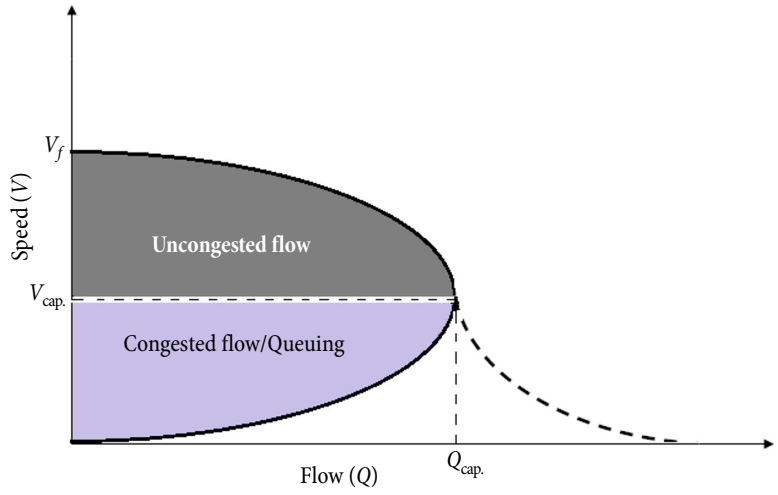

Fig. 1. Uncongested and congested flow parts of speed-flow curve

corresponding to congested and uncongested traffic conditions as shown in Fig. 1 (Yao et. al. 2009). The two segments encompass the following:

- Uncongested (Upper Part): Traffic related to Uncongested and Queue Discharge states;

- Congested (Lower Part): Traffic related to Queuing state (Stop and Go).

The present study analyses two parts separately and determines the speed-flow relationship. Different models including linear, exponential, polynomial, logarithmic and power were attempted to fit the observed speed-flow data. The functional forms of these contestant models are presented in Table 1. An examination of these models revels that exponential equation could be chosen as most promising model to describe the speed-flow relationship at uncongested flow, i.e. the upper part of the curve. Therefore, this model was chosen to fit the data points that correspond to uncongested flow, whereas linier model was selected to describe the speed-flow relationship at congested flow, i.e. the lower part of the curve. Adopting the same procedure, the speed-flow equations for different vehicle types were also developed. The intersecting point of these equations corresponds to possible capacity, and the intercept value of the equation describing upper part of the curve corresponds to FFS.

Table 1. Functional form of contestant equations for speed-flow curves

\begin{tabular}{|l|l|l|}
\hline \multicolumn{1}{|c|}{ Name of the equation } & \multicolumn{1}{|c|}{ Functional form } & \multicolumn{1}{c|}{ Comments } \\
\hline Linear & $V=V_{f}-a \cdot Q$ & $\begin{array}{l}\text { Not acceptable. } \\
\text { It reaches zero speed at high flow. }\end{array}$ \\
\hline Logarithmic & $V=V_{f}-a \cdot \ln Q$ & $\begin{array}{l}\text { Not acceptable. } \\
\text { Has no value at } Q=0 \text { (the logarithm of } Q \text { approaches negative infinity). }\end{array}$ \\
\hline Exponential & $V=V_{f} \cdot e^{-a \cdot Q}$ & It has all the required traits for equilibrium assignment. \\
\hline Power & $V=V_{f} \cdot Q^{-a}$ & $\begin{array}{l}\text { Not acceptable. } \\
\text { It goes to infinity at } Q=0 .\end{array}$ \\
\hline Polynomial & $V=a \cdot Q^{2}-b \cdot Q+V_{f}$ & $\begin{array}{l}\text { Not acceptable. } \\
\text { It reaches zero speed at high flow. }\end{array}$ \\
\hline
\end{tabular}

Notes: $Q$ - flow; $V$ - predicted speed; $V_{f}$ - FFS; $a, b$ - parameters for equation. 


\section{Data Collection}

\subsection{Speed-Flow Study: Registration Plate Survey}

Field studies were carried out to observe SMS and traffic flow data on NH-44 (two-lane highway), a national highway passing through Tripura, a state in the northeast India. Eight segments were selected along $20 \mathrm{~km}$ highway section that approaches Agartala, the capital city of the state, for conducting the study at different traffic flow levels. Traffic volume count using manual count technique was therefore conducted to contemplate the hourly traffic variations. Observations were made on Wednesday (weekday) and Saturday (weekend) respectively. Study was conducted only during day time for 10 hours (from 8:00 am to 6:00 pm) as during night-times traffic flow reduces drastically and also the variety of vehicle categories in the traffic stream is not observed. The recorded data was plotted against time to interpret the hourly traffic variation pattern. Fig. 2 depicts the hourly distribution on the selected highway section.

The study locations were selected with due consideration, so that they were free from the effect of intersection, curvature and ribbon development. Pavement conditions were good and uniform in all the stretches. Video photographic survey technique was adopted to observe the SMS coupled with traffic flow appropriately. Two reference lines $500 \mathrm{~m}$ apart were marked and four observation points were chosen for installing the video cameras; two in each direction, for recording the entry and exit of vehicles. The recordings were synchronized so that extraction errors due to time lag could be avoided. Speed-flow study was subsequently carried out at different flow levels according to the hourly variations on the selected highway segments.

However, the lower part of the curve (Fig. 1), i.e. congested flow, was studied next to a bottleneck created by closing one lane of the two-lane carriageway on the study section. Also, the two-way traffic movements were stopped for two minutes to further examine queuing state when the flow is discharged. In order to ensure adequate sample size for subsequent analysis, few trails were made during peak hours on several days. Traffic police help was taken to conduct the study. Fig. 3 exhibits the video photographic survey on the highway section at uncongested and congested flow respectively.

The video files were played on a computer to extract the traffic data. The necessary readings, i.e. vehicle type, registration number and time, were noted down independently for the four specified locations when a vehicle just crosses the reference line. Form the extracted data, the average travel time taken by vehicles to traverse the reference lines was recorded to compute the SMS. Simultaneously, traffic flow data was also recorded to facilitate the development of speed-flow relationship.

\subsection{FFS: Spot Speed Study}

Field measurement procedure as indicated by HCM was adopted to estimate FFS. The essential prerequisites of field study include an identification of time of the day and duration of low flow condition (two-way flow $\leq$

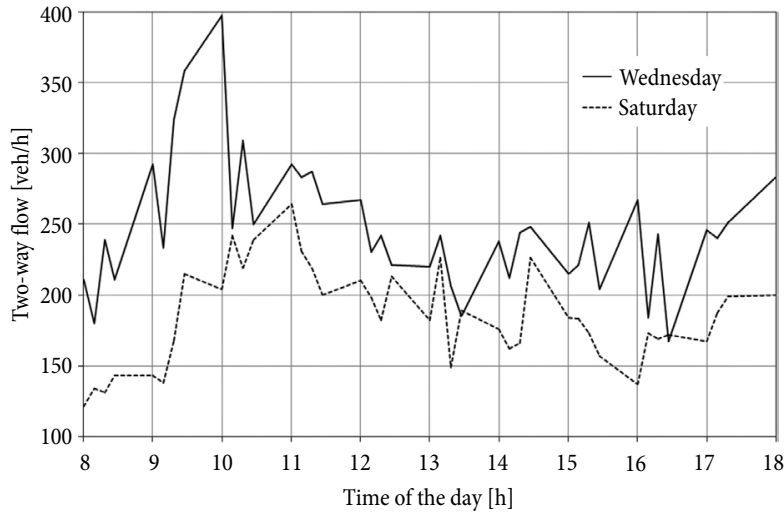

Fig. 2. Observed hourly traffic flow variation on the selected highway section

a)

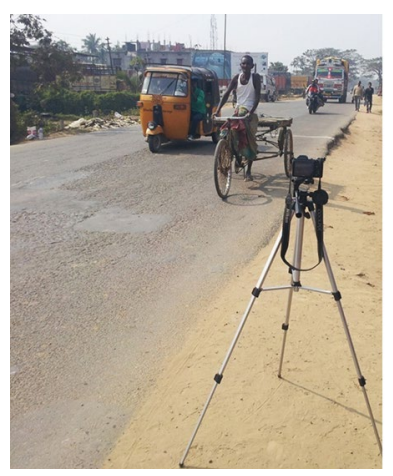

b)

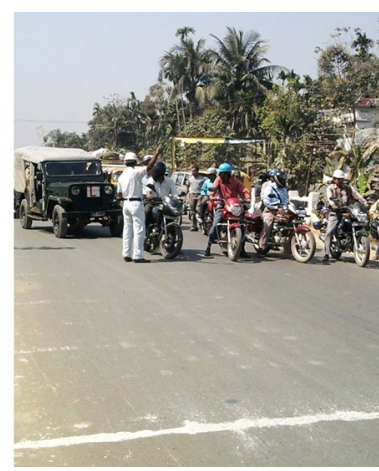

Fig. 3. A view of video photographic survey on the highway section equipped with road markings at: a - uncongested flow conditions; $\mathrm{b}$ - congested flow conditions

200 pc/h). Fig. 2 demonstrates that low-flow condition could be experienced for around two hours during afternoon (01:00-03:00 pm). Thus, spot speed study was conducted at four locations in the study stretch adopting video photographic survey technique only during the identified time. The sections were chosen so as to have a wide variation in the percentage of motorized and non-motorized traffic. Table 2 provides the details of the traffic composition at four different sections selected for the study. Examination of Table 2 reveals that the proportion of para-transit modes including motorized Three-wheeler, Two-wheeler and Non-motorized vehicles increases as the highway approaches the city. Conversely, the proportion of Truck traffic was observed to reduce drastically at study Site- 4 . The reason could be the presence of a bypass route between Site- 3 and Site- 4 that diverts the goods traffic from entering the city.

A video camera was placed away from the longitudinal trap of $10 \mathrm{~m}$ length made on the carriageway so as to avoid any influence in the operating speeds of vehicles. In addition, the video camera was mounted on a stand height of which was adjusted in such a way that it covers the entire trap length keeping some margin on either side. The desired data (entry and exit time of vehicles) was extracted from the recorded video in the laboratory using a computer. The time taken to cover 


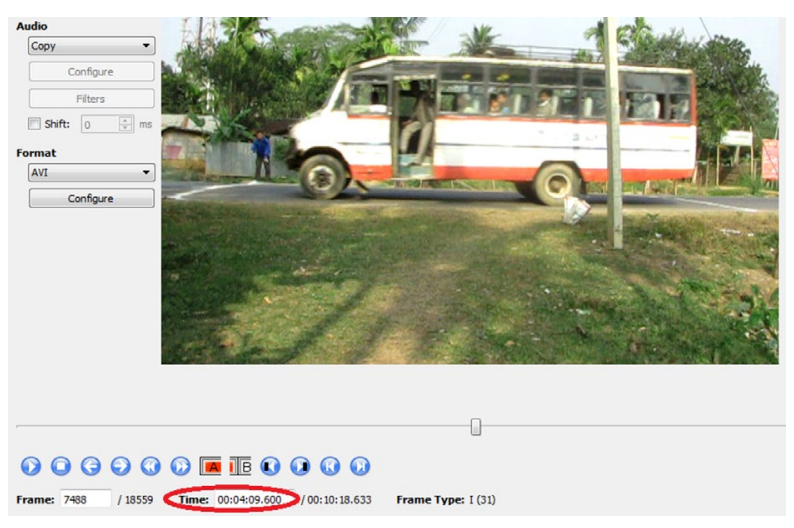

Fig. 4. A view of extraction of entry and exit time of vehicles using Avidemux 2.5

Table 2. Observed traffic composition at study sites

\begin{tabular}{|l|c|c|c|c|}
\hline \multirow{2}{*}{ Vehicle type } & \multicolumn{4}{|c|}{ Traffic composition at study sites [\%] } \\
\cline { 2 - 5 } & Site-1* & Site-2* & Site-3* & Site-4* \\
\hline Passenger car & 35.80 & 35.32 & 30.30 & 23.75 \\
\hline Bus & 5.82 & 5.95 & 5.25 & 6.04 \\
\hline Truck & 25.57 & 26.24 & 17.90 & 8.66 \\
\hline Two-wheeler & 25.93 & 23.90 & 31.08 & 38.06 \\
\hline Three-wheeler & 3.17 & 4.29 & 6.56 & 12.34 \\
\hline $\begin{array}{l}\text { Non-motorized } \\
\text { vehicles }\end{array}$ & 3.70 & 4.29 & 8.92 & 11.15 \\
\hline
\end{tabular}

Note: ${ }^{\star}$ Study sites were selected at an equal distance interval on the selected highway section.

the trap length by each vehicle was measured with an accuracy of $0.01 \mathrm{~s}$ using Avidemux 2.5 software. Fig. 4 exhibits the data extraction process ensuring the desired accuracy level. The lapsed time in covering the trap was used to calculate the spot speed of vehicles. Traffic volume for each road section was also found from the recorded film. The observed speed values were then further analysed and adjusted in accordance with the HCM guidelines to obtain FFS.

\section{Analysis and Results}

\subsection{Free-Flow Speed for Actual Conditions}

According to HCM, the mean value of the measured spot speeds under low-flow conditions can be considered as FFS. However, if field measurement must be made at total flow levels higher than $200 \mathrm{pc} / \mathrm{h}$, the FFS should be estimated incorporating the requisite flow rate corrections as well as adjustments for heavy vehicles. Fig. 2 and Table 2 collectively indicate that the low-flow conditions on the study sites would be rare, thus, the observed mean speeds indubitably would require adjustments.

The coefficient of variation of the speed data was observed to be quite high (ranges between 0.29-0.35). This is in contrast to the coefficient of variation of desired speed, 0.11-0.14 estimated by McLean (1989). Therefore, FFS was estimated taking each motorized vehicle category into consideration separately. Speed data of the four study sites were analysed considering both two-way segment (Highway Capacity Manual 2000) and directional segment (Highway Capacity Manual 2010) methodology. Fig. 5 illustrates comparisons of the values thus obtained. Average FFS was observed to be very close to those estimated for Bus, Truck, Three-wheeler and Two-wheeler respectively, whereas Car's free-speed was observed to be about $5 \mathrm{~km} / \mathrm{h}$ more. However, in case of Non-motorized vehicles, HCM methodology could not be applied because of its dynamic characteristics.

As an alternate, a rural two-lane local road where cycle and pedal tricycle were observed to be predominant was selected for collecting speed data during lowflow condition in order to assess FFS of Non-motorized vehicles. The speed data thus collected was formatted into a frequency distribution table, shown in Table 3.

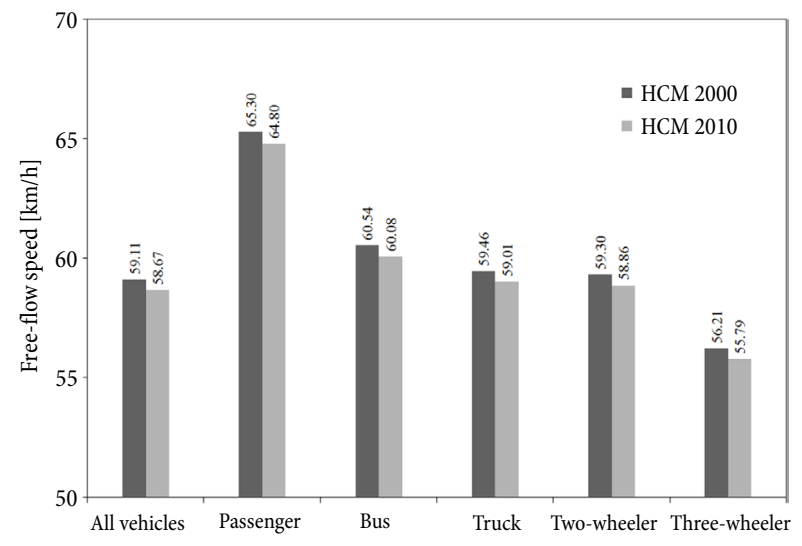

Fig. 5. Comparison of FFSs estimated using HCM

(Highway Capacity Manual 2000, 2010)

Table 3. The details of speed data of Non-motorized vehicles collected on a two-lane road at low-flow condition (two-way flow less than $200 \mathrm{pc} / \mathrm{h}$ )

\begin{tabular}{|c|c|c|c|c|}
\hline \multicolumn{2}{|c|}{ Speed group $[\mathrm{km} / \mathrm{h}]$} & \multirow{2}{*}{$\begin{array}{l}\text { Average speed, } \\
\quad S[\mathrm{~km} / \mathrm{h}]\end{array}$} & \multirow{2}{*}{$\begin{array}{c}\text { Observed } \\
\text { frequency, } n\end{array}$} & \multirow[b]{2}{*}{$n \cdot S$} \\
\hline $\begin{array}{l}\text { Lower } \\
\text { limit }\end{array}$ & $\begin{array}{l}\text { Upper } \\
\text { limit }\end{array}$ & & & \\
\hline 4 & 6 & 5 & 7 & 35 \\
\hline 6 & 8 & 7 & 7 & 49 \\
\hline 8 & 10 & 9 & 57 & 513 \\
\hline 10 & 12 & 11 & 138 & 1518 \\
\hline 12 & 14 & 13 & 97 & 1261 \\
\hline 14 & 16 & 15 & 50 & 750 \\
\hline 16 & 18 & 17 & 16 & 272 \\
\hline 18 & 20 & 19 & 4 & 76 \\
\hline 20 & 22 & 21 & 3 & 63 \\
\hline 22 & 24 & 23 & 2 & 46 \\
\hline \multicolumn{3}{|c|}{ 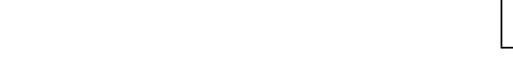 } & 381 & 4583 \\
\hline \multicolumn{5}{|c|}{ Mean or average speed $=\frac{\sum_{i} n_{i} \cdot S_{i}}{N}=$} \\
\hline
\end{tabular}


The guideline used for grouping the data is the Sturges' rule, which stipulates that the width of class intervals should be equal to Range/ $\left(1+3.322 \cdot \log _{10} n\right)$, where: $n$ is the number of observations; Range is the difference between maximum and minimum values of observed speed data. The tabular array shows the total number of vehicles observed in each speed group. For the illustrative study data presented in Table 3, the average or mean speed was found to be $12.02 \mathrm{~km} / \mathrm{h}$.

\subsection{Development of Speed-Flow Equations: Traditional Model}

The observed traffic volume must be converted into a common unit in order to develop speed-flow equations. This is termed as Passenger Car Unit (PCU). The present study uses the PCU factors according to IRC: 64-1990 to express the traffic volume in terms of PCUs. The observed speed-flow data was segregated into uncongested and congested parts. Subsequent to this, speed-flow relationships were developed considering uncongested and congested flow separately. Exponential and linear models were considered for developing the speed-flow equations. Based on applicability, uncongested data was fitted to exponential equation whereas linear equation was considered suitable for congested data. Eqs (1) and (2) present the exponential and linear relationships that best-fit (minimum sum of error squares) the data points of uncongested and congested flow:

$$
\begin{aligned}
& V=64.45 \cdot e^{-0.0003 \cdot Q}, R^{2}=0.89 ; \\
& V=0.013 \cdot Q-0.24, R^{2}=0.77,
\end{aligned}
$$

where: $Q$ - two-way flow $[\mathrm{pc} / \mathrm{h}] ; V$ - the mean speed $[\mathrm{km} / \mathrm{h}]$ measured at flow rate $Q$.

Both the equations exhibit good statistical validity in terms of $R^{2}$ values. Hence, the developed equations Eqs (1) and (2) - are considered appropriate for estimating speeds under varying traffic conditions and can also be explored for evolving roadway capacity. From the Fig. 6, it can be observed that the estimated roadway capacity, i.e. intersecting point of upper and lower curve, is around $2300 \mathrm{pc} / \mathrm{h}$. This is reasonable under mixed traffic flow because the lane space supports two or three rows of narrow vehicles such as bicycles and motorized two-wheelers. Besides, longer delay to the faster vehicles under mixed traffic results in drivers' impatience and acceptance of reduced passing gap, which increases the passing frequency.

Speed-flow relationships were also developed for different vehicle types considering uncongested areas of speed-flow data. The exponential model was considered for developing the speed-flow equations. Fig. 7 illustrates the equations that best-fit the data points. The developed equations for the entire vehicle category, i.e. Car, Bus, Truck, Three-wheeler and Two-wheeler, exhibit good statistical validity in terms of $R^{2}$ values. Figs $7 \mathrm{a}$,

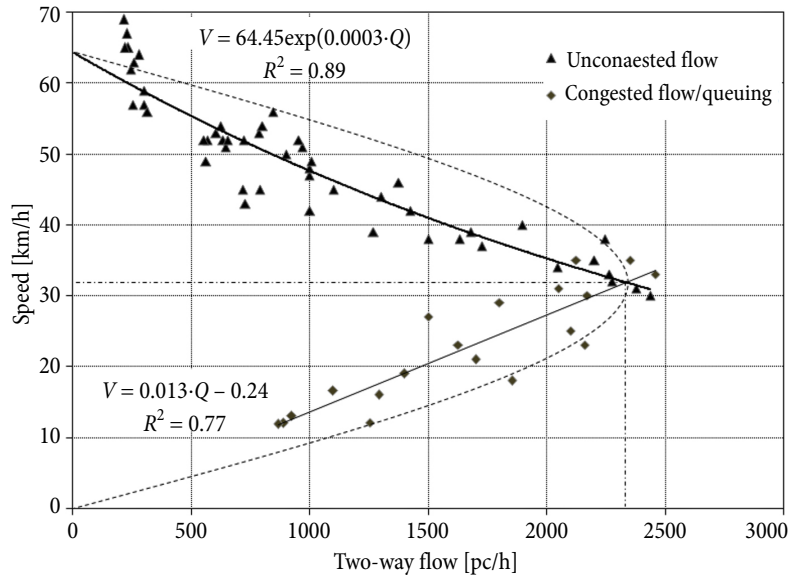

Fig. 6. Speed-flow relationship developed through Traditional Model

d, e depict that speeds of Car, Two-wheeler and Threewheeler fall down gradually from free-speed as the flow increases. The reason could be better manoeuvrability of these vehicle types while performing passing operations. However, the speed of heavy vehicles likes Truck and Bus falls down significantly with the increase of flow because of platoon movements and consequent impedance caused to these vehicles (Figs 7b, c). Manoeuvrability constraint of these vehicles restricts them to perform passing operations frequently accepting minimum passing gap.

To demonstrate the suitability of developed speedflow equations through traditional model, the intercept of the equations were compared with the FFS obtained according to HCM guidelines (refer Fig. 5) and the comparison is presented in Table 4. From Table 4, it can be observed that the error between observed FFS and intercept of speed-flow equations of different vehicle types is ranging from 9 to $0.5 \%$. This indicates that the intercept derived from the traditional models appropriately represented the field conditions as the error difference between the observed FFS and intercept of speed-flow equations of different vehicle types is in conjugation with the assumed working hypothesis, i.e. less than $10 \%$. A further examination of Table 4 reveals that the percent error is maximum when average FFS is compared. This could be attributed to the higher value of standard deviation of the observed data that ranges between 10 $13 \mathrm{~km} / \mathrm{h}$. However, the error difference is considerably less when FFS is compared vehicle category wise.

These consequences difficulties in performance assessment of two-lane highways to traffic analysts involved in the planning and operation of the highway network in India, and arise because of attempt to apply US Highway Capacity Manual $(2000,2010)$ guidelines, which in reality do not describe the traffic characteristics in a mixed-traffic situation. 
a)

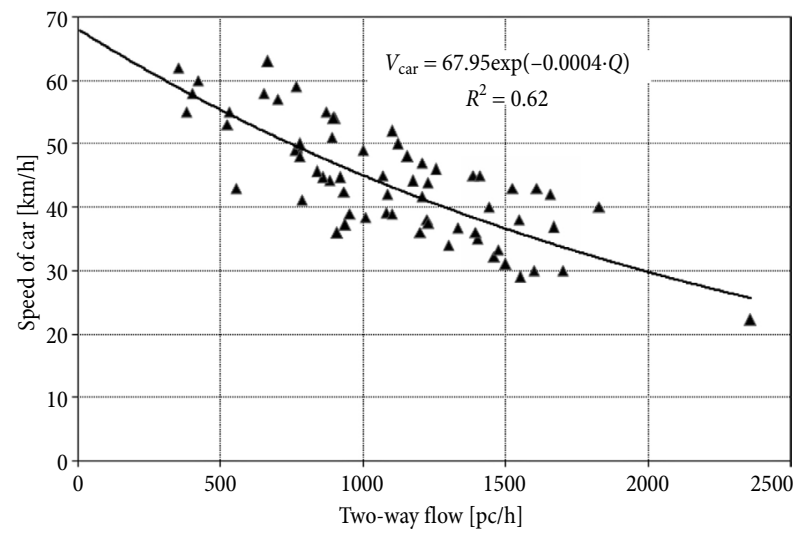

b)



c)

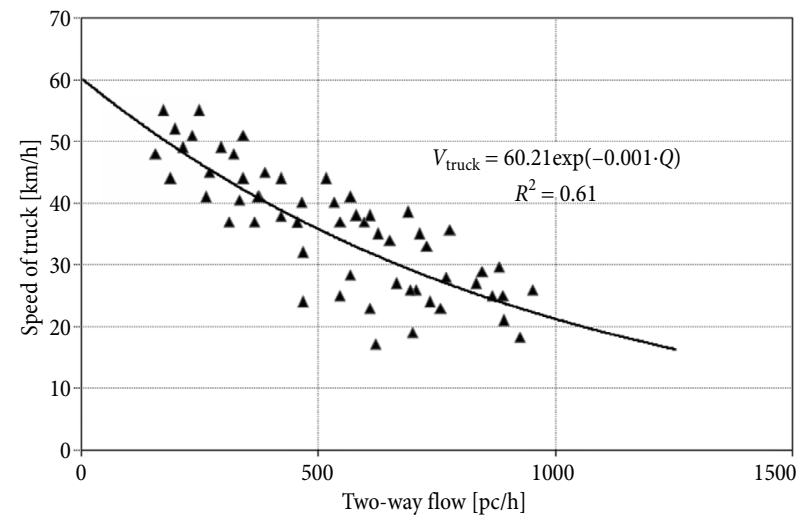

d)

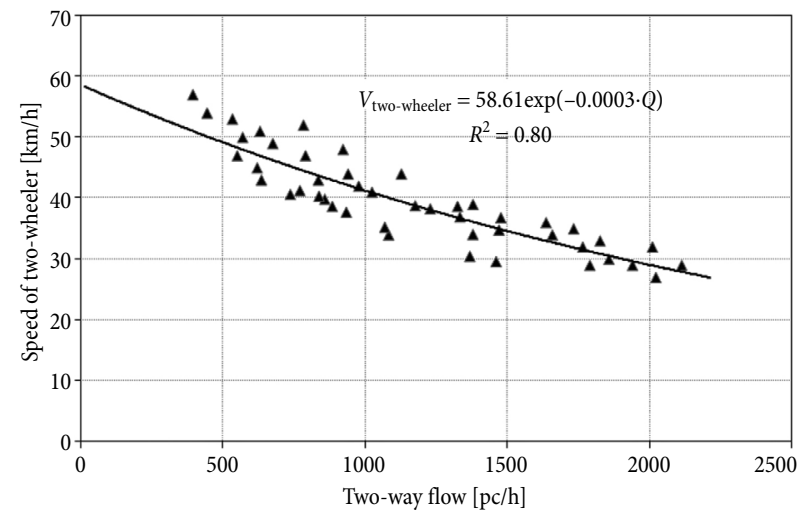

e)

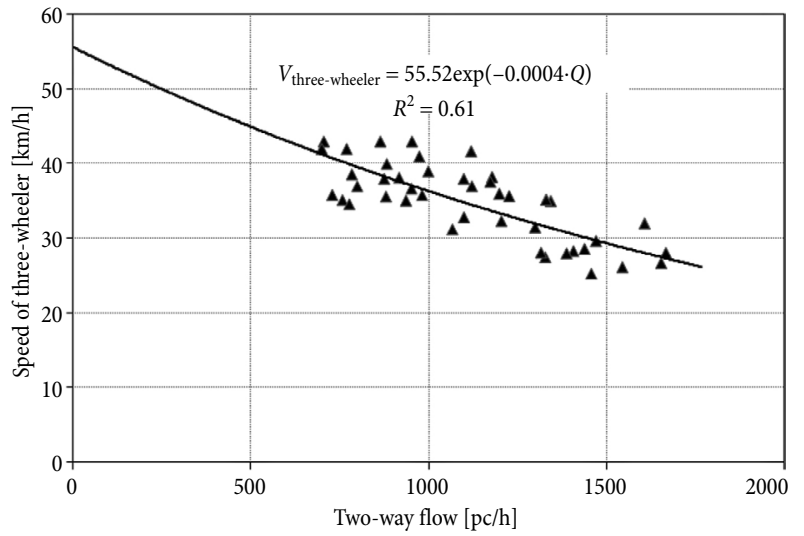

Fig. 7. Speed-flow relationship at uncongested flow condition for: a - car; b - bus; c - truck; d - two-wheeler; e - three-wheeler

Table 4. Comparison of free-speeds estimated based on HCM guidelines with intercept of speed-flow equation

\begin{tabular}{|l|c|c|c|c|c|}
\hline \multirow{2}{*}{ Vehicle type } & $\begin{array}{c}\text { Intercept of } \\
\text { speed-flow equation } \\
{[\mathrm{km} / \mathrm{h}]}\end{array}$ & \multicolumn{2}{|c|}{$\begin{array}{c}\text { FFS estimated based on HCM } \\
\text { (Highway Capacity Manual 2000) }\end{array}$} & \multicolumn{2}{|c|}{$\begin{array}{c}\text { FFS estimated based on HCM } \\
\text { (Highway Capacity Manual 2010) }\end{array}$} \\
\cline { 3 - 6 } & & $\begin{array}{c}\text { Observed FFS } \\
{[\mathrm{km} / \mathrm{h}]}\end{array}$ & $\begin{array}{c}\text { Percent } \\
\text { error }\end{array}$ & $\begin{array}{c}\text { Observed FFS } \\
{[\mathrm{km} / \mathrm{h}]}\end{array}$ & $\begin{array}{c}\text { Percent } \\
\text { error }\end{array}$ \\
\hline All vehicles & 64.45 & 59.11 & 0.083 & 58.67 & 0.090 \\
\hline Passenger car & 67.95 & 65.30 & 0.039 & 64.80 & 0.046 \\
\hline Bus & 64.12 & 60.54 & 0.056 & 60.08 & 0.063 \\
\hline Truck & 60.21 & 59.46 & 0.012 & 59.01 & 0.020 \\
\hline Two-wheeler & 58.61 & 59.30 & 0.012 & 58.86 & 0.004 \\
\hline Three-wheeler & 55.52 & 56.21 & 0.012 & 55.79 & 0.005 \\
\hline
\end{tabular}




\section{Conclusions}

The present study examined the major implication of PFFS, a measure to assess performance on 'Class III' two-lane highways. Extensive speed-flow study was conducted covering wide ranges of traffic flow. At the same time, FFS study was also conducted on the selected highway section. Speed data was analysed considering both two-way and directional segment methodology as indicated by HCM (Highway Capacity Manual 2000, 2010). Exponential model was found to be more acceptable when compared to other competing models to describe uncongested flow, whereas linear equation was considered suitable in case of congested flow. The suitability of developed speed-flow equations through traditional model was further demonstrated by comparing the intercept of the equations with the FFS obtained according to HCM guidelines. The error difference was within the acceptable limit indicating an appropriate representation of the field conditions by the models developed. Comparisons of the average FFS value to the FFS obtained for different vehicle types confirm a very close agreement except for the free-speed of cars that exceeds by about $5 \mathrm{~km} / \mathrm{h}$. While the traffic composition exhibits presence of sizable proportion of cars in the traffic stream a significant error in estimating PFFS would occur. Moreover, the HCM procedure is deficient in determining FFS of Non-motorized vehicles.

The present study indicates that changing freespeed characteristics of different vehicles in heterogeneous traffic stream is the major implication that eventually makes the performance measure, PFFS inappropriate in assessing LOS. Therefore, it is important to identify suitable performance measures to assess the level-of-service on two-lane highways effectively when the prevailing traffic is heterogeneous in character with sizable proportions of both faster and slower vehicles. Further investigations are, therefore, needed to examine the said implications on the current HCM procedures for the determination of LOS for two-lane highways.

\section{References}

Bang, K. L.; Carlsson, A.; Palgunadi. 1995. Development of speed-flow relationships for Indonesian rural roads using empirical data and simulation, Transportation Research Record 1484: 24-32.

Chandra, S.; Kumar, U. 2003. Effect of Lane Width on Capacity under Mixed Traffic Conditions in India, Journal of Transportation Engineering 129(2): 155-160.

http://dx.doi.org/10.1061/(ASCE)0733-947X(2003)129:2(155)

Dey, P. P.; Chandra, S.; Gangopadhaya, S. 2006. Speed distribution curves under mixed traffic conditions, Journal of Transportation Engineering 132(6): 475-481.

http://dx.doi.org/10.1061/(ASCE)0733-947X(2006)132:6(475)

Drake, J. S.; Schofer, J. L.; May, A. D. 1967. A statistical analysis of speed-density hypotheses in vehicular traffic science, Highway Research Record 154: 112-117.

Edie, L. C. 1961. Car-following and steady-state theory for noncongested traffic, Operations Research 9(1): 66-76. http://dx.doi.org/10.1287/opre.9.1.66
Greenberg, H. 1959. An analysis of traffic flow, Operations Research 7(1): 79-85. http://dx.doi.org/10.1287/opre.7.1.79

Greenshields, B. D. 1935. A study of traffic capacity, Highway Research Board Proceedings 14: 448-477.

Highway Capacity Manual. 2010. 5th edition. Transportation Research Board. 1650 p.

Highway Capacity Manual. 2000. Transportation Research Board. $1134 \mathrm{p}$.

Hossain, D. M.; Iqbal, G. A. 1999. Vehicular headway distribution and free speed characteristics on two-lane two-way highways of Bangladesh, Journal of the Institution of Engineers (India): Civil Engineering Division 80: 77-80.

IRC: 64-1990. Guidelines for Capacity of Roads in Rural Areas. Indian Roads Congress, New Delhi, India. 22 p.

Kadiyali, L. R. 1991. Speed-flow characteristics on Indian highways, Journal of the Indian Roads Congress 52(2): 233-262.

Katti, B. K.; Raghavachari, S. 1986. Modelling of mixed traffic speed data as inputs for the traffic simulation models, Highway Research Bulletin 28: 35-48.

Kumar, V. M.; Rao, S. K. 1998a. Headway and speed studies on two-lane highways, Indian Highways 26(5): 23-36.

Kumar, V. M.; Rao, S. K. 1998b. Studies on speed-density-flow relationships on a few stretches of NH-5 and NH-6, Indian Highways 26(12): 33-41.

Leong, H. J. 1968. The distribution and trend of free speeds on two lane two way rural highways in New South Wales, in Proceedings of the 4th Australian Road Research Board (ARRB) Conference, 1968, Melbourne 4(1): 791-814.

Madhu, E.; Velmurugan, S.; Ravinder, K.; Nataraju, J. 2011. Development of free-speed equations for assessment of road-user cost on high-speed multi-lane carriageways of India on Plain Terrain, Current Science 100(9): 1362-1372.

McLean, J. R. 1989. Two-Lane Highway Traffic Operations: Theory and Practice. Gordon and Breach Science Publishers. $418 \mathrm{p}$.

McLean, J. R. 1979. Observed speed distributions and rural road traffic operations, in Proceedings of the 9th Australian Road Research Board (ARRB) Conference, 21-28 August 1978, Brisbane, Australia 9(5): 235-244.

Parker, M. T. 1996. The effect of heavy goods vehicles and following behaviour on capacity at motorway roadwork sites, Traffic Engineering \& Control 37(9): 524-531.

Pillai, K. S.; Ramanayya, T. V. 1977. Traffic inputs for simulation of mixed traffic on a digital computer, in Proceedings of National Systems Conference, June 1977, Coimbatore, India, 66-71.

Pursula, M.; Enberg, A. 1991. Characteristics and level-ofservice estimation of traffic flow on two-lane rural roads in Finland, Transportation Research Record 1320: 135-143.

Rai Chowdhury, M. L. 1993. A Study of Some Traffic Characteristics in an Indian Metropolis and their Application in Simulation of Traffic Flow through a Signalized Intersection: $\mathrm{PhD}$ Thesis. Indian Institute of Technology, Kharagpur, India.

Ramanayya, T. V. 1988. Highway capacity under mixed traffic conditions, Traffic Engineering \& Control 29(5): 284-287.

Sahoo, P. K.; Rao, S. K.; Kumar, V. M. 1996. A study of traffic flow characteristics on two stretches of national highway No. 5, Indian Highways 24(4): 11-17.

Sarna, A. C.; Jain, P. K.; Chandra, G. 1989. Capacity of urban roads - a case study of Delhi and Bombay, Highway Research Bulletin 40: 1-38. 
Tseng, P.-Y.; Lin, F.-B.; Shieh, S.-L. 2005. Estimation of freeflow speeds for multilane rural and suburban highways, Journal of the Eastern Asia Society for Transportation Studies 6: 1484-1495.

Underwood, R. T. 1961. Speed, volume, and density relationship, in Quality and Theory of Traffic Flow, Bureau of Highway Traffic, Yale University, 141-188.

Velmurugan, S.; Madhu, E.; Ravinder, K.; Sitaramanjaneyulu, K.; Gangopadhyay, S. 2010. Critical evaluation of roadway capacity of multi-lane high speed corridors under heterogeneous traffic conditions through traditional and microscopic simulation models, Journal of the Indian Roads Congress 71(3): 235-264.

Yagar, S.; Van Aerde, M. 1983. Geometric and environmental effects on speeds of 2-lane highways, Transportation Research Part A: General 17(4): 315-325.

http://dx.doi.org/10.1016/0191-2607(83)90094-8

Yao, J.; Teng, H.; Wei, H.; Hu, S. 2009. Estimating roadway capacity using the simultaneous spline regression model, Journal of Transportation Systems Engineering and Information Technology 9(1): 87-98.

http://dx.doi.org/10.1016/S1570-6672(08)60047-1 